\title{
Síndrome de Guillain-Barré associada à gastroenterite bacteriana: relato de caso
}

\author{
Guillain-Barré Syndrome associated with bacterial \\ gastroenteritis: case report
}

Aline Pereira Barbalho ${ }^{1}$, Luiza Barbosa Brandão ${ }^{1}$, Mariana Marques Rechuan $^{1}$, Mayara Cristina Barreto Lysandro ${ }^{1}$, Nina Feital Montezzi ${ }^{1}$, Eduardo Tavares Lima Trajano ${ }^{2}$, Adalgiza Mafra Moreno ${ }^{3}$, Aluana Santana Carlos ${ }^{3}$; Victor Hugo Vale Bastos ${ }^{4}$; Silvar Teixeira ${ }^{4}$; Eduardo Jorge Custódio ${ }^{5}$; Marco Orsini ${ }^{2,3,4}$

1.Curso de Medicina da Universidade de Vassouras-RJ, Brasil.

2 Mestrado Profissional em Ciências Aplicadas em Saúde da Universidade de Vassouras-RJ, Brasil.

3 Universidade Iguaçu - UNIG - Rio de Janeiro - Brasil.

4 Programa de Mapeamento Cerebral e Funcionalidade- UFPI.

5.Hospital Pedro Ernesto - UERJ - Departamento de Neurofisiologia.

\section{Resumo}

Objetivo. O objetivo do estudo é relatar um caso de Síndrome de Guillain-Barré (SGB). Método. Paciente do sexo masculino, 20 anos, deu entrada na emergência com quadro de diarreia mucopurulenta, na qual rapidamente progrediu com alteração da sensibilidade dos membros inferiores. Resultados. No decorrer de cinco dias, a parestesia progrediu para membros superiores e tronco, somada a perda de força (grau 2) e disfasia. Diante disso, foi iniciado tratamento empírico com Plasmaférese, com boa resposta terapêutica. Conclusão. A partir dos exames complementares e história clínica do relato concluímos se tratar de um caso de SGB com evolução clássica, entretanto, desencadeado após infecção bacteriana no trato gastrointestinal.

Unitermos. Síndrome de Guillain-Barré; Gastroenterite; Plasmaférese

\begin{abstract}
Objective. The objective of the study is to report a case of Guillain-Barré Syndrome (GBS). Method. A male patient, 20 years old, admitted to emergency room with mucopurulent diarrhea, rapidly progressed with altered sensitivity of lower limbs. Results. Over the course of 5 days, paraesthesia progressed to upper limbs and trunk, in addition to loss of strength (grade 2) and dysphasia. Therefore, empiric treatment with Plasmapheresis was initiated, with good therapeutic response. Conclusion. From the complementary exams and clinical history of the report, we conclude that it is a case of GBS with classic evolution, however, triggered after bacterial infection in the gastrointestinal tract.
\end{abstract}

Keywords. Guillain-Barré Syndrome; Gastroenteritis; Plasmapheresis.

Trabalho realizado Universidade de Vassouras, Vassouras-RJ, Brasil.

Conflito de interesse: não Recebido em: $2018 \quad$ Aceito em: 2018

Endereço para correspondência: Eduardo TL Trajano. Mestrado Profissional em Ciências Aplicadas em Saúde da Universidade de Vassouras-RJ, Brasil. E-mail: eduardolimatrajano@hotmail.com 


\section{INTRODUÇÃO}

A síndrome de Síndrome de Guillain-Barré (SGB) é descrita como uma polineurorradiculopatia imunomediada, inflamatória e desmielinizante aguda ou subaguda que atinge fibras periféricas sensoriais ou motoras ${ }^{1}$. Ocorrem por resposta ao mimetismo celular com formação de anticorpos, ativação do sistema complemento e citocinas. Sua incidência anual é de 1,3 a 1,9 a cada 100.000 habitantes, com idade média de aparecimento de 40 anos e predominância masculina².

Em cerca de dois terços dos pacientes é relatada após infecções agudas do trato respiratório superior ou gastrointestinal que ocorrem até seis meses antes do aparecimento dos sintomas da SBG. A bactéria mais comumente associada a esse quadro é a Campylobacter jejuni, causadora de gastroenterites ${ }^{3,4}$. Relata-se o caso de um paciente, 20 anos, sexo masculino que desenvolveu paralisia motora ascendente após quadro típico de gastroenterite bacteriana.

\section{MÉTODO}

\section{Casuística}

Paciente do sexo masculino, 20 anos, asmático e sem outras comorbidades, apresentou no dia 27 de dezembro de 2015 quadro de diarreia mucopurulenta associada a vômitos e febre alta que se estendeu por quatro dias até a melhora dos sintomas relatados sem uso de medicamentos, apenas com dieta. Dois dias após a melhora, iniciou cólica 
abdominal de forte intensidade queixando-se também de leve alteração de sensibilidade em membros inferiores, descrita como câimbras, e dor em bolsa escrotal, procurando assim o pronto socorro, no qual foram realizados exames laboratoriais e ultrassonografia de abdome e bolsa escrotal, porém, nenhuma alteração foi observada. O paciente recebeu alta fazendo uso de Luftal ${ }^{\circledR}$ e Floratil $® 200 \mathrm{mg}$.

\section{RESULTADOS}

Um dia após a alta hospitalar a cólica abdominal havia melhorado parcialmente, entretanto a parestesia nas pernas apresentou piora, quando fez uso por conta própria de Deocil $®$ e Miosan $®$, sem obter melhora. A parestesia evoluiu gradativamente até que no dia 4 de Janeiro de 2016, ao perceber alteração na força da perna, procurou novamente o hospital. Ao exame realizado no pronto atendimento, paciente encontrava-se eupneico, com bom estado geral, reflexos preservados, alteração de força muscular (grau 3) e sensibilidade de pés e pernas, apresentando sinal de Babinski positivo bilateralmente, sendo assim internado.

Realizou-se punção lombar para análise do líquor, porém, não foi observada nenhuma alteração. No dia 5 de janeiro apresentava-se taquipneico, com parestesia progredindo para os membros superiores e tronco somada a perda de força muscular (grau 2) e disfasia. Foi 
transferido para a unidade de terapia intensiva em virtude da piora do quadro, no qual foi iniciado tratamento empírico com Plasmaférese, iniciado no $4^{\circ}$ dia de internação sendo administrado por quatro dias.

No $6^{\circ}$ dia de internação apresentou melhora do estado geral e retorno dos movimentos do pescoço e membros superiores, alívio da parestesia em todo o corpo. No 70 dia conseguiu sentar-se e mover levemente as pernas com auxílio da fisioterapia. No $8^{\circ}$ dia de internação recebeu alta para o quarto e evoluiu bem até o $10^{\circ} \mathrm{dia}$, quando recebeu alta hospitalar. Após um mês de fisioterapia domiciliar o paciente conseguiu voltou a deambular encontrando-se sem sequelas até o momento.

Após a alta realizou-se a eletroneuromiografia que evidenciou quadro sugestivo de polirradiculopatia desmielinizante acometendo os quatro segmentos com sinais de degeneração axonal nos músculos distais dos membros inferiores. Tal quadro, associado à história clínica sugere o diagnóstico de Síndrome de Guillain-Barré desencadeada por gastroenterite.

\section{DISCUSSÃO}

A SGB é uma condição autoimune incomum, caracterizada por fraqueza bilateral progressiva e reflexos diminuídos ${ }^{5}$. Atualmente, é considerada a primeira causa de paralisia flácida aguda nos países desenvolvidos com uma 
incidência anual de 1,3 1,9/100000 habitantes. Acredita-se que o aumento da incidência verificado nos últimos anos, traduz uma melhoria na acuidade diagnostica mais do que um aumento do número de casos $^{6}$.

Atinge em sua maioria o sexo masculino, podendo ocorrer em todas as idades, com um $1^{0}$ pico no final da adolescência e início da idade adulta, que coincide com um aumento do risco de infecção pelo citomegalovírus e Campylobacter jejuni. Cerca de $2 / 3$ dos doentes com SGB referem um antecedente infeccioso agudo, geralmente uma infecção gastrointestinal ocorrida 1 a 3 semanas antes, e que normalmente se encontra resolvida na altura do diagnóstico. Em muitos casos o agente patológico permanece sem identificação ${ }^{7}$. Nos paciente que tiveram a gastroenterite, a infecção por Campylobacter jejuni e as formas axonais da doença são especialmente comuns. $O$ lipo-oligossacarídeo da parede bacteriana $C$ jejuni contém estruturas semelhantes a gangliosídeos ${ }^{8}$ e induz a formação de anticorpos anti-GM1 que reagem de forma cruzada com os tecidos neurais, associando-se a uma variante motora pura e com pior prognóstico ${ }^{7}$. Em modelos animais, esses anticorpos anti-gangliosídeos induzem a lesão axonal fixando o complemento, recrutando macrófagos e depositando complexo de ataque à membrana na membrana axolêmica. Essa cascata imunológica interrompe a integridade anatômica e fisiológica das membranas nervosas expostas nos terminais nervosos causando um bloqueio de condução nervosa. No entanto, a interação 
entre fatores microbianos e do hospedeiro que determina se e como a resposta imune é deslocada para a auto reatividade indesejada ainda não está bem entendido e os, fatores genéticos e ambientais que afetam a suscetibilidade de um indivíduo a desenvolver a doença é desconhecida ${ }^{9,10}$.

Os sintomas iniciais consistem em parestesia nas mãos e pés, e ocasionalmente dor nos membros inferiores, seguida de fraqueza muscular com início nos membros inferiores. Essa fraqueza é progressiva e afeta sucessivamente pernas, braços, músculos respiratórios e os núcleos dos nervos cranianos, configurando um quadro clínico de paralisia ascendente ${ }^{6}$.

O diagnóstico é amplamente baseado em padrões clínicos, porque biomarcadores não estão disponíveis para a maioria das variantes da síndrome ${ }^{9}$ e os exames laboratoriais são de pouca ajuda no início do processo. 0 líquor mostra uma elevação de proteínas (maior que 50 $\mathrm{mg} / \mathrm{dL}$ ) que só é detectada após 1 semana do início dos sintomas, o que justifica o exame de líquor sem alterações no nosso caso. Essa concentração é máxima entre a $2^{a}$ e $4^{a}$ a semanas, com células escassas (menos de 10 células mononucleares/dl), o que constitui a chamada dissociação albumino-citológica. O estudo eletrofisiológico é o exame mais sensível e específico para o diagnóstico, demonstrando inúmeras alterações que indicam desmielinização e disfunção axonal, como ocorreu em nosso caso ${ }^{6}$. 
O início da recuperação é variado, com a maioria dos indivíduos apresentando recuperação gradual da força muscular 2 a 4 semanas após o início do quadro ${ }^{6}$. Taxas de mortalidade entre pacientes com SGB na América do Norte e Europa variam de $3 \%$ a $7 \%$, com morte mais frequentemente resultante de insuficiência respiratória, disfunção autonômica ou trombose venosa profunda ${ }^{5}$.

A SGB é uma doença potencialmente fatal. Tanto os cuidados médicos gerais como o tratamento imunológico são essenciais. Atenção meticulosa aos cuidados de suporte é necessária para prevenir ou administrar complicações. As medidas incluem o monitoramento da função respiratória pela medição frequente da capacidade vital e outros desfechos clínicos, e a transferência oportuna para a UTI quando necessário ${ }^{9}$. Atualmente, o tratamento consiste essencialmente em medidas de suporte médico e de imunomodulação ${ }^{7}$ pelo uso da imunoglobulina endovenosa ou da Plasmaférese ${ }^{6}$ que devem ser iniciadas o mais rápido possível antes que ocorra dano irreversível ao nervo.

Ambas parecem estar relacionadas com evolução clínica mais rápida e uma menor quantidade de complicações e sequelas. Para o uso da plasmaférese, é necessário que o paciente esteja compensado do ponto de vista hemodinâmico. A sua efetividade estaria relacionada com menor tempo de uso de ventilação mecânica e retorno à aquisição dos padrões de deambulação. Cinco sessões de troca de plasma (cada troca compreendendo 2-3L de plasma de acordo com o peso corporal) durante duas 
semanas é o regime benéfico aceito, quando iniciado dentro das primeiras quatro (de preferência duas) semanas de início em pacientes com síndrome de Guillain-Barré ${ }^{9}$. Por sua vez, o uso de imunoglobulina é seguro, fácil, de rápida avaliação e não oferece os riscos da circulação extracorpórea. Embora seu mecanismo de ação ainda não esteja totalmente esclarecido, sabe-se que essa droga altera diretamente a imunidade dos pacientes. Como a geralmente tem efeitos colaterais menores, substitui a troca de plasma como o tratamento preferido em muitos centros $^{9}$.

As opiniões divergem quanto ao uso de corticoides no SGB, estudos apontam que tanto os esteróides orais como a metilprednisolona intravenosa não são benéficos no distúrbio ${ }^{9}$. Ainda em fase experimental está, por exemplo, o uso de interferon beta, existindo ainda outras perspectivas para tratamento futuro desta síndrome tais como o uso de fator de crescimento do nervo, citocinas imunomoduladoras, e prevenção, eliminação e controlo de certas infecções por Campylobacter jejuni ${ }^{7}$.

A atuação da fisioterapia em casos de SGB visa à reabilitação funcional do paciente, utilizando estratégias terapêuticas como mobilização passiva para a manutenção da amplitude de movimento articular, alongamentos com objetivo de evitar contraturas articulares e encurtamentos musculares e mudanças periódicas de decúbito na prevenção de úlceras ${ }^{11,12}$. 


\section{CONCLUSÃO}

A partir dos exames complementares e história clínica do relato concluímos se tratar de um caso de SGB com evolução clássica, entretanto, desencadeado após infecção bacteriana no trato gastrointestinal, provavelmente por Campylobacter jejuni, dada a sua comum relação com a enfermidade.

\section{REREFÊNCIAS}

1.Guillain G, Barré JA, Strohl A. Sur un syndrome de radiculoneurite avec hyperalbuminose du liquide cephalo-rachidien sans reaction cellulaire; remarques sur les caracteres cliniques et graphiques des reflexes tendineux. Bull Soc Med Hop Paris 1916;40:462.

2. Honavar M, Tharakan KJ, Hughes RAC. A clinicopathological study of the Guillain-Barré syndrome: nine cases and literature review. Brain 1991;114:1245-69. https://doi.org/10.1093/brain/114.3.1245

3.Schwerer B. Antibodies against gangliosides: a link between preceding infection and immunopathogenesis of Guillain-Barré syndrome. Microbes Infect 2002;4:373-84.

https://doi.org/10.1016/S1286-4579(02)01550-2

4.Dourado J, Teixeira ME. Síndrome de Guillain-Barré: epidemiologia, prognóstico e fatores de risco (Tese). Natal: Centro de Ciências da Saúde, Universidade Federal do Rio Grande do Norte, 2015, 90p.

5.Dirlikov E, Major CG, Medina NA, Lugo-Robles R, Matos D, MuñozJordan JL, et al. Clinical Features of Guillain-Barré Syndrome With vs Without Zika Virus Infection, Puerto Rico, 2016. JAMA Neurol 2018;75:1089-97.

https://doi.org/10.1001/jamaneurol.2018.1058

6.Orsini M, Mello MP, Reis JPB, Antonioli RS, Santo VV, Freitas MRG. Síndrome de Guillain-Barré na infância: relato de caso. Rev Neurocienc 2007;15:329-33.

7.Fonseca T, Cardoso T, Perdigão S, Sarmento A, Morgado R, Costa M. Síndrome de Guillain-Barré. Acta Med Port 2004;17:119-22.

8. Hughs RA, Cornblath DR. Guillain-Barré Syndrome. Lancet 2005;366(9497):1653-66. $\quad$ https://doi.org/10,1016/S01406736(05)67665.9

9. Willison $\mathrm{HJ}$, Jacobs BC, Doorn PA. Guillain-Barré Syndrome. Lancet 2016;388:717-27. https://doi.org/10.1016/S0140-6736(16)00330-1 10.Jasti K, Selmi A, Sarmiento-Monroy C, Vega JCA, Anaya D, Gershwin JME. Guillain-Barré syndrome: causes, immunopathogenic mechanisms and treatment. Exp Rev Clin Immunol 2016;12:6-13. 
11.Orsini M, Freitas MRG, Nascimento OJM, Catharino AMS, Mello MP, Reis CHM, et al. Síndrome de Guillain-Barré pós-infecção por dengue: Relato de Caso. Rev Neurocienc 2010;18:24-7.

12.Lamônica DAC, Pereira TC, Silva KR, Lopes AC. Relato de caso: Síndrome de Guillain-Barré - atraso do desenvolvimento da linguagem. Rev Med 2009;88:199-202. 